\title{
Engineering Education in the 21st Century
}

\author{
Ralph O. Buchal \\ The University of Western Ontario
}

\begin{abstract}
Changing educational needs and reduced funding for traditional educational institutions are forcing a reexamination of the educational process. At the same time, emerging information technologies are enabling a transition from traditional instructor-centred teaching to a new model based on student-centred collaborative learning. The importance of the physical university is diminishing as information technology enables learning to occur anywhere, at any time. This paper describes the new model of collaborative learning, and evaluates emerging technologies to support it.
\end{abstract}

\section{Introduction}

We live in a time of unprecedented change. All aspects of our society and economy are being transformed as we move to a knowledge-based economy. Education is becoming increasingly important, yet funding for traditional educational institutions is being cut. Universities must transform themselves to address changing educational needs.

For knowledge workers, work and learning are becoming the same thing ${ }^{1}$. Learning is becoming problem-driven, as people continuously seek new knowledge to tackle new problems. In the new team-based organization, work and learning are becoming interdisciplinary and collaborative in nature. People need to learn on a just-in-time basis, from wherever they are, whenever is convenient to them.

Learning has been traditionally centred at formal schools and universities. Historically, universities made sense as a place where scholars and experts gathered, and where existing knowledge was archived in large physical libraries. A learning environment was established by the intermingling of students and professors, with access to a large library.

Information technology promises to shift learning away from formal institutions. It is now possible to bring students and professors together in virtual learning networks. Also, as information becomes accessible from anywhere, the importance of physical libraries will diminish. It is clear that universities must adapt, or risk becoming irrelevant.

\section{A New Model of Collaborative Learning}

The conventional model of education is based on the transmission of information and knowledge from the teacher to the students. A fundamentally new model of collaborative learning is beginning to emerge to replace the traditional model. This new model is driven by society's changing needs, and is enabled by 
information technology. Progressive educators are exploiting computer-mediated communication (CMC) technologies to establish on-line learning networks ${ }^{2,3}$. The old and new models are compared below ${ }^{4}$

\begin{tabular}{|l|l|}
\hline Old model & New model \\
\hline Classroom lectures & Individual exploration \\
\hline Passive absorption & Apprenticeship \\
\hline Individual work & Team learning \\
\hline Stable content & Fast-changing content \\
\hline Homogeneity & Diversity \\
\hline
\end{tabular}

\section{Classroom lectures vs. Individual Exploration}

The classroom lecture is usually a highly-structured forum for delivering information from the professor's notes to the students' notes. The course content is compiled and organized by the teacher. The new model places responsibility with the student to seek and explore information from many sources, and to synthesize a deeper knowledge and understanding of the material.

\section{Passive Absorption vs. Apprenticeship}

Too often, traditional engineering education relies on the passive absorption of information. Engineering problem solving tends to be mechanistic, relying on highly repetitive solutions of simple, idealized, linear problems. Laboratory experiments frequently have a cook-book approach, with little opportunity for individual exploration.

The new model seeks to develop knowledge and skills through experimentation and exploration of more complex engineering problems. These activities are supported by computer models and simulations, which permit exploration of many more "what-if" scenarios than are possible with conventional experiments and assignments.

\section{Individual Work vs. Team Learning}

Conventional wisdom holds that the highest level of achievement for an engineering student is the ability to work independently. This ability is developed by stressing individual work and individual evaluation.

The increasing importance of collaborative work has lead to an important realization - the ability to work interdependently, as part of a team, is a higher level of achievement than working independently. Business managers have discovered that empowered teams collaborate to achieve impressive results with minimal supervision ${ }^{5}$. Similarly, students can learn and achieve more as a collaborative team than as a group of individuals.

According to Michael Schrage,

...collaboration is the process of shared creation: two or more individuals with complementary skills interacting to create a shared understanding that none had previously possessed or could have come to on their own. Collaboration creates a shared meaning about a process, a product, or an event ${ }^{6}$. 


\section{Stable vs. Fast-Changing Content}

There are many anecdotal accounts of professors lecturing from notes that haven't been revised in decades. While some parts of the engineering curriculum are relatively stable, other areas are changing constantly. For example, textbooks in fast-moving fields like information technology, computer engineering, telecommunications, etc., are outdated before they are printed. It has become very difficult for professors to stay current in these fields, particularly if they are teaching a course outside their research areas. By accessing a variety of information sources, students and teachers collaborate in learning and staying abreast of developments.

\section{Homogeneity vs. Diversity}

It is now recognized that students come from diverse backgrounds, and have a variety of abilities and learning styles. Teaching approaches that treat students as a homogeneous group are no longer appropriate. Learning must be based on a variety of tools and methods.

\section{Modes of Delivery}

The traditional lecture mode of teaching has changed little for centuries. In light of changing needs and a shift of emphasis from teaching to learning, new modes of delivery need to be developed and exploited. The table below illustrates how different modes of educational delivery can be classified according to the temporal and spatial relationship between the student and the instructor.

\begin{tabular}{|l|l|l|}
\hline & Synchronous (Same Time) & Asynchronous (Different Time ) \\
\hline $\begin{array}{l}\text { Collocated } \\
\text { (Same } \\
\text { Location) }\end{array}$ & Classroom lecture & CBT/multimedia \\
& $\begin{array}{l}\text { Discussion groups, tutorials } \\
\text { Laboratories }\end{array}$ & Internet \\
& Demonstrations & File sharing \\
Computer simulations \\
Virtual Reality
\end{tabular}

It is important to note that effective methods for distance education delivery have existed for many decades already. Also, computer-based methods can be used effectively in all four quadrants. However, the greatest promise of information technology is to allow effective learning to occur anytime, anyplace.

\section{Using Technology to Teach the Old Way}

Computers and information technology offer many of the tools necessary to support the new model of learning. However, these technologies are frequently used to buttress the traditional educational model instead. Interactive multimedia courseware and videoconferencing are two technologies that are frequently used this way. 


\section{Interactive Multimedia Courseware}

Many educators see development of interactive multimedia courseware as an important prelude to effective use of computers in the classroom. Good courseware of this type is very time-consuming and expensive to develop, with typical estimates of $\$ 100 \mathrm{~K}$ per course. This multimedia courseware is usually distributed on CD-ROM.

In the author's opinion, multimedia courseware is rooted in the old model of learning. Multimedia CDROM courseware is frequently criticized as being no more than a "talking textbook", and there is some truth in this comparison. Although the multimedia courseware can contain much richer media than any book, it is still the exclusive creation of the course author. The amount of interaction and exploration is often limited to carefully prescribed paths. Furthermore, the content is static and updating is difficult.

\section{Videoconferencing}

Fully interactive, two-way videoconferencing is rapidly becoming one of the preferred modes of distance education delivery. The technology is impressive and expensive. However, videoconferencing is too often used to broadcast a traditional lecture to students over a distance. Furthermore, it is a synchronous technology, so learning can take place anyplace, but only at the same time.

\section{Technologies that Support Collaborative Learning}

\section{Effective Synchronous And Asynchronous Communication}

Collaboration requires effective communication. A variety of tools have emerged to support both synchronous and asynchronous communication. A few of these tools are listed below.

\begin{tabular}{|l|l|}
\hline Synchronous Communication & Asynchronous Communication \\
\hline Videoconferencing & email \\
\hline Whiteboard and application sharing & newsgroups and bulletin boards \\
\hline Audiographic conferencing & fax \\
\hline Chat & \\
\hline Teleconferencing & \\
\hline
\end{tabular}

Engineering communication has always been a multimedia activity, using text, diagrams, drawings, mathematics, images, physical models, etc. Traditional communication tools include the blackboard, sketch pad, notebook, and the proverbial "back of the envelope".

Current synchronous communication tools such as videoconferencing and audiographic conferencing can effectively replace the blackboard and other traditional media, but these tools are still weak in their ability to record and archive the results of the collaborative activity. Current asynchronous communication tools are primarily text-based. These tools can maintain a record of discussions and collaborative activities, but they are weak in support for multimedia.

\section{Easy Access To Information And Experts}

Data and information are the raw materials from which knowledge and understanding are built. As shared knowledge and understanding are constructed, the search for information becomes focused rather than 
random, and questions become well defined. For example, students working on a particular design problem may quickly identify the need for information about material properties and selection. Traditionally, this would lead to a lengthy search of library resources, and questioning of available experts, often professors stopped in the hallway. Using information technology, it is now possible to find information within seconds from any networked computer, and to ask questions of the leading experts in the world.

\section{Shared Workspaces}

A shared workspace is an essential element of collaboration. One of the most important tools available to collaborators has been and remains the humble blackboard. The blackboard has significant limitations, however: it has no memory after it is erased; users must be collocated; its size is physically limited; objects can't be easily moved around on it; and so on.

Computer-based tools promise to remove these limitations by providing a virtual shared workspace for collaborators located anywhere. Some useful tools are beginning to emerge, such as computer whiteboard and application-sharing programs. These tools permit collaborators to interact with a shared computer screen over a network. Despite their promise, these tools still lack many important capabilities. This may be due in part to a poor understanding of the nature of collaboration.

Traditionally, engineers have maintained a personal engineering notebook, which serves as a permanent record and archive of engineering calculations, design decisions, ideas, etc. Few equivalent tools exist for collaborative engineering. What is needed is a shared multimedia database that serves the same purpose as the engineer's notebook. This is a very important area of technology development for collaborative engineering education.

\section{Modelling, Analysis And Simulation Tools}

Engineers have always constructed models to help understand and communicate the behavior of real systems. Educators are beginning to make more extensive use of powerful computer modelling and simulation software. These tools promote a deeper understanding of the mathematical models used to represent real systems, and facilitate "what-if" exploration of alternatives. Many of these tools are becoming available at low cost on standard desktop computers.

\section{Visualization and Virtual Reality}

Visualization and representation of three dimensional objects has always been a central part of engineering. Spatial visualization and reasoning are considered to be critical abilities for students to develop. Students are trained to map 3-D objects to sets of 2-D views, and to reconstruct 3-D objects from those views.

Perhaps it is time to consider whether this is a fundamental skill, or whether it's an artifact of traditional limitations of the media. Interactive three-dimensional graphics and virtual reality hold great promise as tools for engineering. Low-cost computer game systems are approaching the capabilities of multimillion-dollar flight simulators of only a few years ago. Emerging standards such as Virtual Reality Modelling Language (VRML) permit the construction and manipulation of 3-D environments over a network. In the near future, most engineering design will be done in virtual 3-D space, and 2-D representations will become unnecessary. 


\section{Shared Multimedia Document Creation And Publishing}

Construction of a shared knowledge base is an important objective of collaborative learning. The ability to synthesize information and experience into knowledge and understanding has traditionally been developed through the writing of student reports, papers and theses. This remains largely a solitary activity, and the resulting work is usually seen only by the instructor. Group reports are typically constructed by assigning sections or chapters to each team member, and joining the sections together at the end. This approach has been partly dictated by a lack of tools for collaboration.

Tools are now available to permit shared creation of rich multimedia documents by teams of students. These documents can then be contributed to a common knowledge base. The Internet can be considered a globally distributed, shared knowledge base.

\section{A Case study: The University Space Network Pilot Project}

The University Space Network (USN) Pilot Project is a multi-institution collaboration established in 1995 to develop and offer a multimedia-based course in Spacecraft Systems Design. The university participants of USN are the University of Western Ontario, University of Windsor, Ryerson Polytechnical University, Queen's University, and Royal Military College of Canada. University of Toronto and York University are affiliated, and University of Guelph and Lakehead University are observing. Other participants include Spar Aerospace Ltd., Marc Garneau Collegiate Institute, and the Institute for Space and Terrestrial Studies (ISTS), and the Knowledge Connection Corp.

Content experts at the participating institutions developed multimedia courseware modules for distribution on CD-ROM, using an experimental authoring tool called Virtual Lesson Technology (VLT). Teams of about eight students at each site worked collaboratively on a major spacecraft design project, drawing on the multimedia courseware, the Internet, textbooks, and email communication with the content experts. There were no formal lectures or tutorials. The site coordinators acted as facilitators rather then instructors.

The student teams achieved outstanding results with minimal supervision. The students collaborated closely on all aspects of the project, and it was difficult to distinguish individual contributions. The groups worked very effectively by consensus, without a designated leader, and all students contributed equally to the team effort. Assessment of individual marks was difficult, and it was agreed by consensus that all team members should receive the same team mark.

While it was very useful, the multimedia courseware was considered to be just one available resource. The students also sought information from the library and from the Internet. Surveys indicated that the students spent the majority of their course time on collaborative activities rather than individual tasks. The students felt that teamwork was a critical element of this course.

This project has demonstrated that development of an infrastructure to support collaborative learning is at least as important as the development of courseware. There was extensive communication and collaboration between students at each site, but relatively little communication between sites. An important challenge will be to build an enabling infrastructure to achieve the same level of collaboration between virtually collocated teams, distributed among several sites.

This project highlighted the difficulty of assessing and grading students working as part of a team. It can be destructive to team dynamics and cohesion to attempt to rank team members relative to each other. On the other hand, contributions to the team performance are not always equal. Our current assessment methods are 
designed to measure independent, individual achievement. New methods for assessing interdependent, group achievement are needed.

\section{Conclusions}

Networked collaborative learning is emerging as a new paradigm of education for the 21 st century. This shift is driven by changing educational needs of the new knowledge economy, and is supported by emerging information technologies. A partnership between educators and technology developers is needed to make effective use of existing technologies, and to identify where better supporting technologies are necessary.

\section{References}

\footnotetext{
${ }^{1}$ Tapscott, Don, The Digital Economy: Promise and Peril in the Age of Networked Intelligence, McGraw-Hill, p. 198

${ }^{2}$ Harasim, L., Hiltz, S. R., Teles, L., Turoff, M., Learning Networks: A Field Guide to Teaching and Learning Online, MIT Press, 1995.

${ }^{3}$ Ellsworth, Jill H., Education on the Internet, Sams Publishing, 1994.

${ }^{4}$ Reinhardt, Andy, “New Ways to Learn”, Byte, March 1995, pp. 50-72.

${ }^{5}$ Sherman, Stratford, “Secrets of HP's 'Muddled' Team”, Fortune, Vol. 133, No. 5, March 18, 1996

${ }^{6}$ Shrage, Michael, No More Teams: Mastering the Dynamics of Creative Collaboration, Currency Doubleday, 1995, p.31.
}

\section{Ralph O. Buchal}

Dr. Buchal earned a degree in Mechanical Engineering from the University of British Columbia in 1980. He subsequently earned an M.A.Sc. in 1984 and a Ph.D. in 1987, both from U.B.C. He has been a faculty member in the Department of Mechanical Engineering at the University of Western Ontario since 1987. Prof. Buchal's interests include robotics, manufacturing, information technology, and computer-integrated manufacturing. He has been active in curriculum and undergraduate laboratory development in these areas. He teaches courses in Robotics and Manufacturing Automation, Production Management for Engineers, and Computer Systems and Engineering Applications. He is a content provider, site coordinator and Chair of the Technical Subcommittee of the University Space Network Pilot Project. He is a member of IEEE, ASEE and the Institute of Industrial Engineers. 